\title{
Assessment of Hormonal Contraceptives Use Among Early Married Women in Qena City
}

\section{Asmaa A Sayed $^{\text {a }}$, Ahmed M. M.Hany ${ }^{\text {b }}$, Mahmoud S Iwes ${ }^{c}$}

${ }^{a}$ Department of Public Health and Community Medicine, Faculty of Medicine, South Valley University , Qena, Egypt.

${ }^{b}$ Department of Public health and Community Medicine, Faculty of Medicine, Assiut University, Assiut, Egypt.

${ }^{c}$ Department of Obstetrics and Gynecology, Faculty of Medicine, South Valley University, Qena, Egypt

\begin{abstract}
:
Background: Marriage in young age is a very common problem in Egypt. According to Central agency for public mobilization and statistics in Egypt, Qena is the first government in early marriage by 12.8 per 1000 person. This indicates the great reproductive problem that faces women like unintended pregnancy and maternal mortality.
\end{abstract}

Objectives: Assessment effect of marriage age on contraceptives behaviors. Also, to identify other factors that can affect using of hormonal contraception methods like education, husband opinion about family planning idea and socioeconomic level.

Patients and methods: At family planning clinics of five primary health care units in Qena city this cross-sectional study was conducted on 400 married females in reproductive aged 15:49 years to detect relation between marriage before legal age (18 years) and practicing family planning. There are two groups, female married before 18 years and that married at or after 18 years. A structured questionnaire was used.

Results: There is a significant relation between marriage age and hormonal contraceptives use, about $73.2 \%$ of female included in our study use contraception methods and married after age of eighteen (pvalue $=0.001)$. According to logistic regression analysis husband opinion is the most contributing factor associated with use of Contraception ( $p$ - value $<0.0001)$ while the least contributing factor is husband education $(\mathrm{P}-\mathrm{value}=0.064)$.

Conclusion: Using of hormonal contraception was low among females married before age of eighteen so their family size is higher. Education plays a vital role in practicing family planning.

Keywords: hormonal contraceptives, early married, family planning

\section{Introduction:}

Marriage before age of eighteen is one of most common problem in our Arab society. There is a strong bond between early marriage and maternal morbidity or mortality (Cloward,2016). Most of girls marry below legal age (18 years) more liable to unwanted pregnancies and risk of STD; all these conditions affect mother and infant health. About 16 million young ladies give births and ninety five percent of these births occur in developing countries (Neal et al.,2018).
According to Egypt Demography and Health survey 2014 (EDHS,2014) the median age of marriage among females in reproductive age is 20.8 years old. In rural, females marry in younger age than in urban by four years (Yaya et al.,2021).

Despite government effort in adapting family planning practice and combating early marriage but it still a national problem that need more studies consider social norms and cultural barriers that hinder use of contraception (Coll,2019).

Copyright: (C) Sayed et al. (2022) Immediate open access to its content on the principle that making research freely available to the public supports a greater global exchange of knowledge. Users have the right to Read, download, copy, distribute, print or share link to the full texts under a Creative Commons BY-NC-SA 4.0 International License. 
In 2015, According to United Nations program the crude birth rate was $60 \%$ in last 10 years in South America and North Africa. During 2014 the total fertility rate increased to 3.5 (Telch and Isaza ,2020).

There are many demographic features that affect contraceptive behavior like education level, family size and socioeconomic level (Hailemariam and Haddis, 2011).

The ministry of health provides the contraception methods in primary health care unit and family planning center in very low price and train the health care team how to meet needs of the clients and to improve service quality (Saad Farrag,2020).

The proportion of females ever use modern family planning methods in Egypt is $79 \%$ (Kavleetal.,2015).

\section{Patients and methods}

A cross-sectional study was carried out to detect the relationship between marriage age and contraceptives behaviors among Married females in the Reproductive Age in Qena city. This study was conducted at family planning clinics of primary health care units in Qena city. By a systematic random sampling technique, five Primary Health Care (PHC) centers were selected while the participants were selected from each unit by simple random sample. Data were collected on a practice base from women that go to family planning centers. Sample size was estimated to determine a prevalence of marriage in young age among married Women in Reproductive Age (MWRA) of $4 \%$ with a $2 \%$ acceptable margin of error and $95 \%$ level of confidence. The estimated sample size is 369 , we raised it up to 400 participants.

\section{Inclusion criteria}

All married women in reproductive age (15-49 years) attending family planning centers and approved to participate in the study were enrolled.

\section{Exclusion criteria}

Unmarried women and those outside the reproductive age range (15-49 years).

\section{Data collection}

Data were collected during December 2020 to May 2021. The interviews were targeting married
Women in Reproductive Age attending PHC. The interviews conducted one time a week with an average of 20 purposively selected women per day in the PHC's waiting area. The interview questionnaire was adapted from a Korean study that explores the relationship between fertility and other variables. The questionnaire including the following element that concerns our study:

$\square$ Demographic characteristics: Age, education level, family size and socioeconomic level which was adapted from modified scale of Fahmy and Elsherbini which consist of ten dimension (education level of the mother and father, work of mother ,work of father, computer use, family income, family size, crowding index, proper sewage disposal and proper refuse disposal)

(Fahmyet al.,2015).

Marital characteristics: Age of marriage.

$\square$ Family planning practices: contraceptive use and timing, side effect, sources, types of contraception method and attitude towards practicing family planning.

$\square$ Barriers to using family planning methods.

A pilot study was conducted on 40 subjects (approximately $10 \%$ of the sample size) to pre-test the questionnaire and changes were made accordingly.

The study was reviewed by the ethical committee of Qena Faculty of Medicine and was approved.

\section{Data management and statistical analysis}

All the statistical analyses were done using the IBM SPSS (Statistical Package for the Social Science; IBM Corp, Armonk, NY, USA) release 26 for Microsoft Windows for data analysis). Qualitative variable will be recorded as frequencies and percentages and will be compared by chi-square test. Quantitative measure will be presented as means \pm standard deviation (SD) and will be compared by student $\mathrm{t}$ - test. Regression analysis and correlation between different variable will be performed as indicated. $\mathrm{P}$ value $<0.05$ will be significant.

\section{Results}

A total of 400 females in reproductive age (15-49) were included in this study, the mean age was $29.78+6.54$ years, $63.8 \%$ of them age of marriage were below 18 years and $66.8 \%$ were from rural. 
$59.8 \%$ of the studied women use family planning methods. From the total number of studied women, $38.25 \%$ had attended below secondary education. The details of demographic and socioeconomic characteristics of the women are shown in (Table.1).

Table 2 and Fig. 1 showed that among the studied women in the age group (15-49) $26.8 \%$ of them use family planning methods, with age of marriage $<=18$ years while $73.2 \%$ of them use family planning, with age of marriage " >18" (p- value <0.0001) which show highly statistically significant relation between age of marriage and using of contraception.

Although , $65.3 \%$ of women who came from rural areas use family planning compared to $34.7 \%$ in urban areas (p-value $=0.4$ ) there is no statistically significant relation between resident and using of family planning. Concerning the family size, among the studied women the family size 7 members o or above $12.6 \%$ use family planning methods, while $48.8 \%$ of women with family size 5 members use family planning methods ( $\mathrm{p}$ - value $<0.0001)$ as shown in table 2.

In table (3), 26\% of studied women had attended below secondary education use contraception methods while $74 \%$ of women had attended secondary and above education use contraception. Concerning husband's education, $34.7 \%$ of husbands had attended below secondary education use contraception methods while $65.3 \%$ of husbands had attended secondary and above education use contraception.

Concerning socioeconomic level, $15.9 \%$ of studied women of high socioeconomic level use contraception methods while $69.8 \%$ of women of middle socioeconomic level use contraception. All these variables were highly statistically significant $(\mathrm{P} \leq 0.002)$ as shown in Table-3.
Table (4) show highly statistically significant relation between husband opinion in using contraception and practicing of family planning ( $\mathrm{P}$ - value $<0.001$ ) as $76 \%$ of husbands of women in the study accept using of contraception by their wives who already use method while $61.2 \%$ of husbands not accept using of family planning methods and their wives not use any contraception methods.

Table (5) illustrate logistic regression analysis for factors affect using of hormonal contraception among the studied women in Qena City there were 6 factors associated with the using of family planning methods among married female in reproductive age in Qena City, the most contributing factors for using of methods were husband opinion in the use of the method $(\mathrm{P}<\quad 0.0001)$, family size number $(\mathrm{P}<$ $0.002)$, and age of marriage $(\mathrm{P}<\quad 0.002)$ then socioeconomic level $(\mathrm{P}<0.003)$, education of wife (P-value0.004), while the least contributing factor was husband education (P-value0.064).

$20 \%$ of the women participating in the study stated that the reason for not practicing family planning was the lack of privacy while obtaining the method while $17.5 \%$ believed that the fear of the side effects of the family planning method was one of the most important obstacles to them. $20 \%$ of the women in the study told us that their husbands reject the idea of using them as a means of family planning and prevent them from practicing it, while $7.5 \%$ consider it to be incompatible with their religious beliefs. 
Table 1: Demographic characteristics of the studied women $(\mathrm{N}=400)$

\begin{tabular}{|c|c|}
\hline Parameters: & \\
\hline $\begin{array}{c}\text { Age in years (Mean } \pm \text { SD) } \\
\text { Age of marriage }\end{array}$ & $29.78 \pm 6.53$ \\
\hline$\square=<18$ & $\mathrm{~N}(\%)$ \\
\hline$>18 \quad$ Residence: & $255(63.8 \%)$ \\
\hline Rural & $145(36.3 \%)$ \\
Urban & $\mathrm{N}(\%)$ \\
\hline Very low & $267(66.8 \%)$ \\
Low & $133(33.2 \%)$ \\
\hline Middle & $\mathbf{N}(\%)$ \\
\hline High & $20(5 \%)$ \\
\hline Education level of women: & $89(22.25 \%)$ \\
\hline Below secondary & $251(62.75 \%)$ \\
\hline Secondary and above & $40(10 \%)$ \\
\hline Education level of husband: & $\mathbf{N}(\%)$ \\
\hline Below secondary & $154(38.5 \%)$ \\
Secondary and above & $246(61.5 \%)$ \\
\hline
\end{tabular}

Table 2: Relationship between family planning usage and demographic characteristics of the studied women

\begin{tabular}{|c|c|c|c|c|}
\hline \multirow[t]{2}{*}{$\begin{array}{l}\text { Demographic } \\
\text { characteristics }\end{array}$} & \multicolumn{2}{|c|}{$\begin{array}{l}\text { Using family planning } \\
\text { (yes) }\end{array}$} & \multirow{2}{*}{$\begin{array}{c}\text { using family } \\
\text { planning } \\
(\mathrm{No})\end{array}$} & \multirow[t]{2}{*}{$\mathrm{P}$ value } \\
\hline & Total & $\mathrm{N}(\%)$ & & \\
\hline \multicolumn{5}{|c|}{ Age of marriage } \\
\hline$<=18$ & 145 & $64(26.8 \%)$ & $81(50.2 \%)$ & \multirow{2}{*}{$<0.0001$} \\
\hline$>18$ & 255 & $175(73.2 \%)$ & $80(49.7 \%)$ & \\
\hline \multicolumn{5}{|c|}{ Resident } \\
\hline Urban & 133 & $83(34.7 \%)$ & $50(31.1 \%)$ & \multirow{2}{*}{0.4} \\
\hline Rural & 267 & $156(65.3 \%)$ & $111(68.9 \%)$ & \\
\hline \multicolumn{5}{|c|}{ Family size } \\
\hline$>=7$ & 50 & $30(12.6 \%)$ & $20(12.4 \%)$ & \multirow{4}{*}{$<0.0001$} \\
\hline 6 & 52 & $42(17.6 \%)$ & $10(6.2 \%)$ & \\
\hline 5 & 169 & $119(48.8 \%)$ & $50(31.1 \%)$ & \\
\hline 3,4 & 129 & $48(21 \%)$ & $81(50.3 \%)$ & \\
\hline
\end{tabular}

$\otimes \quad$ Chi square test 


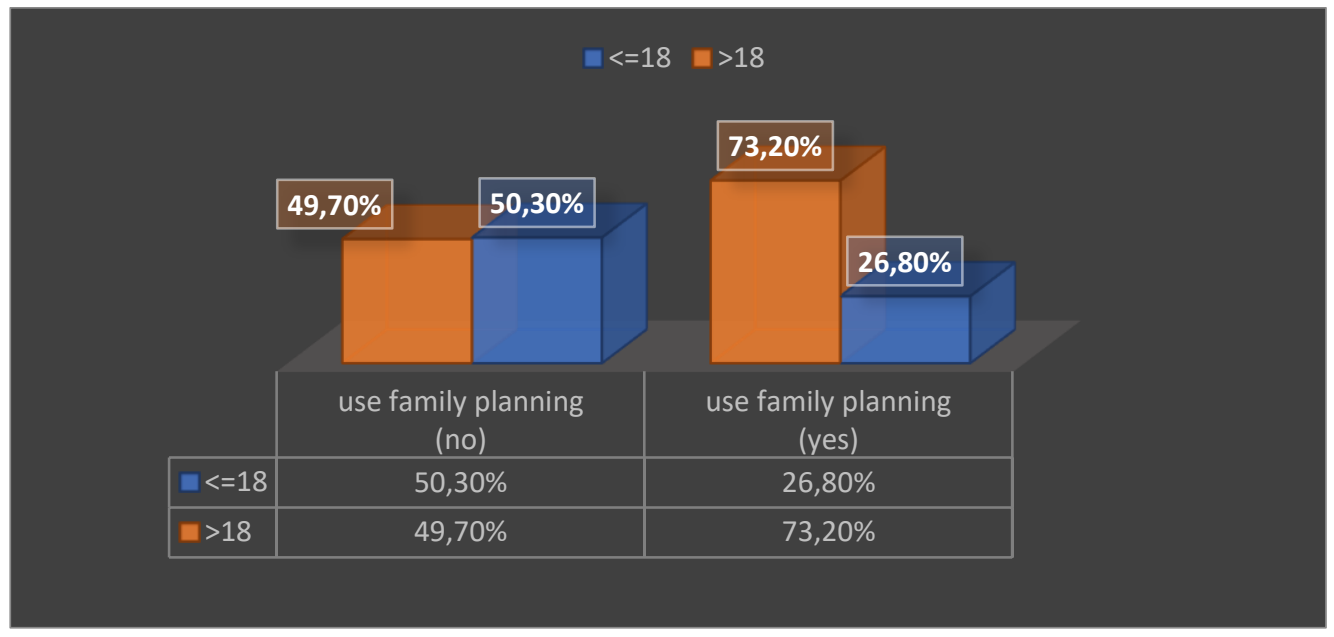

Fig.1. Frequency distribution of family planning usage according to age of marriage.

Table:3 Relationship between family planning usage and education and socioeconomic level

\begin{tabular}{|c|c|c|c|}
\hline Variables & $\begin{array}{c}\text { Using family planning } \\
\text { (yes) } \\
\text { N (\%) }\end{array}$ & $\begin{array}{c}\text { Using family planning } \\
\text { (NO) } \\
\text { N (\%) }\end{array}$ & P-Value \\
\hline \multicolumn{4}{|c|}{ Wife education level } \\
\hline Below secondary & $62(26 \%)$ & $91(56.5 \%)$ & \\
\hline Secondary and above & $177(74 \%)$ & $70(43.5 \%)$ & $<0.0001$ \\
\hline \multicolumn{4}{|c|}{ Husband education level } \\
\hline Below secondary & $83(34.7 \%)$ & $94(58.4 \%)$ & \multirow{2}{*}{$<0.0001$} \\
\hline Secondary and above & $156(65.3 \%)$ & $67(41.6 \%)$ & \\
\hline \multicolumn{4}{|c|}{ Socioeconomic level } \\
\hline High & $38(15.9 \%)$ & $2(1.2 \%)$ & \multirow{4}{*}{0.002} \\
\hline Middle & $167(69.8 \%)$ & $84(52.13 \%)$ & \\
\hline Low & $34(14.3 \%)$ & $55(34.27 \%)$ & \\
\hline Very low & $0(0 \%)$ & $20(12.4 \%)$ & \\
\hline
\end{tabular}

* Chi square test 
Table 4: Relationship between husband opinion and usage of family planning methods

\begin{tabular}{|c|c|c|c|}
\hline $\begin{array}{l}\text { Husband opinion in using of contraception } \\
\text { methods }\end{array}$ & $\begin{array}{l}\text { Using family } \\
\text { planning } \\
\text { (yes) } \\
\mathrm{N}(\%)\end{array}$ & $\begin{array}{l}\text { Using family } \\
\text { planning } \\
(\mathrm{NO}) \\
\mathrm{N}(\%)\end{array}$ & P-value \\
\hline Accept using of contraception & $171(76 \%)$ & $54(24 \%)$ & \multirow{2}{*}{$0.001^{* *}$} \\
\hline Not accept using of contraception & $68(38.8 \%)$ & $107(61.2 \%)$ & \\
\hline
\end{tabular}

\section{Chi square test}

Table 5: Multivariate Logistic regression analysis for factors affects using of hormonal contraception among the studied women in Qena City

\begin{tabular}{|c|c|c|c|c|}
\hline Variable & Odds ratio & \multicolumn{2}{|c|}{ 95\% CI } & \multirow{2}{*}{ P Value } \\
\cline { 3 - 4 } & OR & Lower & Upper & \\
\hline Husband opinion in use this method & 4.98 & 3.24 & 7.67 & $<0.0001$ \\
\hline Family size number & 0.53 & 0.33 & 0.86 & 0.002 \\
\hline Age at marriage & 2.77 & 1.82 & 4.22 & 0.002 \\
\hline Socioeconomic level & 5.26 & 3.26 & 8.47 & 0.003 \\
\hline Education of wife & 3.71 & 2.43 & 5.68 & 0.004 \\
\hline Education of husband & 2.64 & 1.75 & 3.98 & 0.064 \\
\hline
\end{tabular}

\section{Discussion}

This study presents an overview of family planning practices among married women in the reproductive age group living in Qena city. Overall, we found that the use of the FP method was lower among early married before 18 years as compared to those married after the age of 18 years. Among the studied population the mean age of early marriage < 18 was 17 -year-old, representing $63.8 \%$ of the study sample. Comparatively to the EHIS, where only $4 \%$ of women in the reproductive age group (15-49) consider it best for a girl to marry before her 18th birthday (Bruce and Clark,2004). This could be attributed to the fact that this study was conducted in upper Egypt specifically $(66.8 \%)$ of participants were from rural community where early marriage is a strong social norm.

The EHIS shows that $91.7 \%$ of women age 15-49 years approving the use of FP methods and $89 \%$ of those living in rural areas within the same age group. This differ from findings of this study is only $59.8 \%$ of participant use family planning methods and $65.2 \%$ of them were from rural area as sample size used in our study were smaller.

Internationally, education consider most important determinant in practicing family planning. Education is a systematic effort that lasts a lifetime in order to divert the knowledge from one person to another. A person who has received a higher education is usually more able to accept new things that would be considered advantageous for him. A Study conducted by Tilahun T. et al determines unmet need for family planning among married couples in Jimma zone, Ethiopia. Date was collected from 854 married couples using a multistage sampling design (Tilahun etal ,2013).Education is the most important factor associated with better knowledge about contraceptive methods $(\mathrm{p}<0.001)$, especially among women. this agree with our study as $25.9 \%$ of 
studied women had attended below secondary education use contraception methods while $74 \%$ of women had attended secondary and above education use contraception ( $p$ value $<0.0001$ ).

In Giza, A cross-sectional study was conducted to detect the relationship between the age of marriage and FP practices among Married females in the reproductive age. (Mowafy and Kamal Elden, 2020) Based on the result of the current study $87 \%$ of the above secondary educated women practiced FP, comparing to our study $74 \%$ of participant who practice family planning were above secondary education ( $p$ - value $<0.0001$ ).

A secondary analytic study based on EDHS 2008 data conducted in Assuit, Egypt by Manal et al. explored that husband education is a strong significant predictor of hormonal contraception usage ( $\mathrm{p}$ value <0.0001) (Hamza and Darwish, 2019).This completely agree with our study as Concerning husband's education, $37.4 \%$ of husbands had attended below secondary education their wives use contraception methods while $65.2 \%$ of husbands had attended secondary and above education their wives use contraception ( $\mathrm{p}$ value $<0.0001$ ). Several studies states that there is a significant relationship between husband support and contraceptive use by women who married at an early age in the Aikmel Sub-District East Lombok District (Laput et al ,2021). If the husband supports using contraceptives, females will continue to practice family planning. while that does not have the support of a husband will be less of contraception users (Bongaarts and Bruce, 1995).

Nzokirishaka and Ituaproved that the husband's desire to have offspring is a main factor affecting the need for practicing family planning. Unmet need for spacing was less likely when the couple wanted the same number of children, or the husband wanted more, or fewer children compared to his wife ignoring their husband's fertility intentions ( $p$ - value <0.0001) (Nzokirishaka and Itua,2018). This finding agreed with our study as in our study we found a strong relationship between husband situation about family planning using and spacing between children ( $p$ - value $=0.001$ ). In
Indonesia, husband support to use family planning method by his wife play a vital role in using contraceptives at beginning of marriage and 5 time stronger than lacking husband support (Amra ,2018).

Economical level play important role in whether a woman will use contraception or not. In developing country man has upper hand in financial issues so most of wives can't get access to family planning methods without the support of their husband. According to Duru and Chukwuma B, people who have high incomes were more likely to use family planning methods than those with low income. Also, those who can afford family planning service cost without their husband's support were more likely to use than those who cannot pay without their husband support. This indicate the vital role of socioeconomic status of women $(p$-value $=0.001)$ (Duru, 2018). This agree with our study as only $14.2 \%$ of studied women of low socioeconomic level use contraception methods while $69.8 \%$ of women of middle socioeconomic level use contraception ( $\mathrm{P}$ value=0.002). This call for making family planning services for free so all women can afford it.

There are a lot of barriers to use contraceptives among non-users and previous users. $20 \%$ of the women participating family planning in our studystated that the reason for not practicing family planning was the lack of privacy while obtaining the method, Studies carried out in Nepal and Jordan showed that the administrative barriers were obvious because of problems in the health care system and lack of good counseling by health care providers( Storey and Boulay,2000).

\section{Conclusion}

Family planning method use was particularly low among females married before 18 and consequently, their family size and their pregnancy number were high. Education is a significant determinant of the age of marriage and of FP use. These factors should be considered during the design of short- term and long-term family planning strategies to effectively increase 
family planning methods use among early married females. also, husband opinion and support to use family planning methods is a very effective factor so we must involve men in the campaign that spread knowledge about the important of family planning.

\section{References}

- ArmaAJ (2018). Enhancement of peer companian role in avoiding drug usage through the entrepreneurial group in mabar urban village, medan deli sub-district of medan city. Abdimas talenta: Jurnal Pengabdian Kepada Masyarakat,

- 3(1): 24-2.

- BruceJ, Clark S (2004).Early marriage and HIV risks in sub-Saharan Africa. Studies in family planning, 35(3):149-160.

- BongaartsJ, BruceJ (1995). The causes of unmet need for contraception and the social content of services. Studies in family planning,27(4): 57-75

- Cloward K (2016). When norms collide: Local responses to activism against female genital mutilation and early marriage. Oxford University Press,33(2): 54-71.

- Coll C, Ewerling F, Hellwig F, De Barros A (2019). Contraception in adolescence: the influence of parity and marital status on contraceptive use in 73 low-and middleincome countries. Reproductive health, 16(1): 112-117.

- Duru CB(2018). Socio-Demographic Determinants of Family Planning Service Utilization among Women of Reproductive Age in Urban Communities of Imo State, Nigeria. Open Access Library Journal, 5(05): 139-143.

- Fahmy SI, Nofal LM, Shehata SF, El Kady HM, Ibrahim HK (2015).Updating indicators for scaling the socioeconomic level of families for health research. Journal of the Egyptian Public Health Association, 90(1): 1-7.

- HailemariamA, Haddis F (2011). Factors affecting unmet need for family planning in southern nations, nationalities and people's region, Ethiopia. Ethiopian journal of health sciences, 21(2): 77-90.
- Hamza WS, Darwish MM (2019). Determinants of family planning use among currently married women aged 1549 years and their partners: a secondary analysis based on the Egypt Demographic and Health Surveys, 2000 and 2008. Egyptian Journal of Community Medicine, 37(3): 111-115.

- Kavle JA, El-Zanaty F, LandryM, Galloway $\mathbf{R}$ (2015). The rise in stunting in relation to avian influenza and food consumption patterns in Lower Egypt in comparison to Upper Egypt: results from 2005 and 2008 Demographic and Health Surveys. BMC Public Health, 15(1): 1-18.

- Kirk D, Pillet B (1998). Fertility levels, trends, and differentials in sub-Saharan Africa in the 1980s and 1990s. Studies in family planning,3(1): 1-22.

- LaputDO, ManonggaSP, MuntasirM, PadengEP, Nanur FN (2021). Factors predicting of the Implant Contraceptive Used as Family Planning Method among Mothers in Wae Mbeleng Public Health Center, Ruteng Sub District. International Journal of Nursing and Health Services (IJNHS), 5(1):97-111.

- Mowafy M, Kamal Elden N (2020). Assessment of Contraception Use among Early Married Females in Rural Districts in Giza Governorate, Egypt. The Egyptian Family Medicine Journal, 4(1): 127-143.

- Neal S, Channon A,ChintsanyaJ (2018). The impact of young maternal age at birth on neonatal mortality: Evidence from 45 low- and middle-income countries. Plos one, 13(5):148-155

- Nzokirishaka A, Itua I (2018). Determinants of unmet need for family planning among married women of reproductive age in Burundi: a crosssectional study. Contraception and reproductive medicine, 3(1): 1-13.

- Saad FN (2020). Practice of Family Planning among Married Female Attendants to Shawa Family Health Unit, Dakahlia, Egypt. The Egyptian Family Medicine Journal, 4(1): 24-41. 
- Storey JD, Boulay M (2000). Improving family planning use and quality of services in Nepal through the entertainmenteducation strategy. Summary and Update of Field Report No, 12.

- Telch F, Isaza C, Rubaii N (2020). Governance challenges within national development planning: lessons from the Colombian experience. International Review of Public Administration, 25(3): 175-191.

- TilahunT, Coene G, LuchtersS, Kassahun W, Leye E, TemmermanM, et al. (2013). Family planning knowledge, attitude and practice among married couples in Jimma Zone, Ethiopia. Plos one, 8(4): 13-25

- YayaS,Hudani A, Buhm A, Bishwajit G. (2021). Prevalence and predictors of intimate partner violence among married women in Egypt. Journal of interpersonal violence, 36(2122): 10686-10704. 